chemotherapy with radiotherapy conferred better OS than chemo alone (36 months vs 4 months, $\mathrm{p}=0.006$ ).

Conclusion* Non-uterine carcinosarcomas had poorer survival than their uterine counterparts. Our cohort of uterine carcinosarcomas had more patients with early-stage disease.. Nodal involvement carries poor prognosis. On subgroup survival analysis, adjuvant radiation in combination with chemotherapy showed benefit, with significant effect seen in stage III cancers.

\section{CIMICIFUGA RACEMOSA EXTRACT EFFECTS ON ENDOMETRIAL AND OVARIAN CELL LINES}

M Sinreih*, K Gregoric, K Marton, T Lanisnik Rizner. faculty of medicine, university of ljubljana

\subsection{6/ijgc-2021-ESGO.168}

Introduction/Background* In postmenopausal women estrogen levels depend exclusively upon the local formation from steroid precursors dehydroepiandrosterone-sulfate and estrone-sulfate (E1-S). The reduced estrogen levels are associated with menopausal symptoms, which often occur in peri- and postmenopausal patients. To mitigate these symptoms nowadays more women choose medicine of natural origin, e.g. extracts from Cimicifuga racemose (CE) instead of hormone replacement therapy, which is associated with increased risk of breast cancer, stroke and pulmonary embolism. While CE treatment is considered as safe, little is known about its effects on healthy endometrial or ovarian tissue and even less on hormone-dependent malignancies like endometrial and ovarian cancer that arise in this population of women. The aim of our study was to examine the influence of CE on the expression of genes encoding E1-S transporters and estrogen biosynthetic and metabolic enzymes in control and cancerous endometrial and ovarian cell lines.

Methodology Control endometrial cell line (HIEEC), control ovarian cell line (HIO80) and cell lines of well differentiated endometrial carcinoma (Ishikawa and HEC-1-A), moderately differentiated adenosquamous carcinoma (RL-95-2), poorly differentiated endometrial carcinoma (KLE) and high grade ovarian serous adenocarcinoma (Kuramochi, COV62 and OVSAHO) were exposed to $\mathrm{CE}$ in different concentrations for 72h. The expression of 9 E1-S transporter genes (SLCO4C1, SLC51A, ABCC1, ABCC4, SLC10A6, SLCO1A2, SLCO2B1, SLCO3A1, SLCO4A1) and 4 genes encoding estrogen biosynthetic/metabolic enzymes (HSD17B1, HSD17B2, STS and SULT1E1) and estrogen receptors (ESR1 and ESR2) were measured using RT-qPCR.

Result(s)* The results revealed that CE affects the expression of genes encoding E1-S transporters and estrogen biosynthetic and metabolic enzymes only at very high concentrations of CE $(50 \mu \mathrm{g} / \mathrm{ml}$ or $100 \mu \mathrm{g} / \mathrm{ml})$, while no changes in expression were observed with concentrations that are similar to those detected in plasma of CE users.

Conclusion* Our research presents an insight of CE effects on endometrial or ovarian cancer CLs at the mRNA level showing additional proof of safe usage of CE in healthy women and women with hormone-dependent malignancies like endometrial and ovarian cancer.

\section{MOLECULAR FEATURES AND PROGNOSTIC IMPACT OF MELF TYPE MYOMETRIAL INVASION IN THE PORTEC-1/2 COHORT OF EARLY STAGE ENDOMETRIAL CANCERS}

${ }^{1}$ AS Van den Heerik*, ${ }^{2} \mathrm{~K}$ Aiyer, ${ }^{3}$ J Jurgenliemk-Schulz, ${ }^{4} \mathrm{~J} J o b s e n,{ }^{5} \mathrm{JW}$ Mens, ${ }^{6} \mathrm{~L}$ Lutgens, ${ }^{5} \mathrm{R}$ Nout, ${ }^{1} \mathrm{CL}$ Creutzberg, ${ }^{2} \mathrm{~V}$ Smit, ${ }^{1} \mathrm{~N}$ Horeweg, ${ }^{2} \mathrm{~T}$ Bosse. ${ }^{1}$ Leiden University Medical Center (LUMC), Radiation Oncology, Leiden, Netherlands; 'Leiden University Medical Center (LUMC), Pathology, Leiden, Netherlands; ${ }^{3}$ UMC Utrecht, Radiation Oncology, Utrecht, Netherlands; ${ }^{4}$ MST, Radiation Oncology, Enschede, Netherlands; ${ }^{5}$ Erasmus MC, Radiation Oncology, Rotterdam, Netherlands; ${ }^{6}$ Academic Hospital Maastricht, Radiation Oncology, Maastricht, Netherlands

\subsection{6/ijgc-2021-ESGO.169}

Introduction/Background* Microcystic, elongated fragmented (MELF) pattern of myometrial invasion is a distinct histologic feature occasionally seen in low-grade endometrial carcinomas (EC). The prognostic relevance of the presence of MELF is uncertain due to conflicting data and has not appropriately been studied in the context of the novel molecular EC classification. We aimed to determine the relation of MELF pattern of invasion with clinicopathological and molecular characteristics, and define its prognostic relevance in early stage (high) intermediate risk EC.

Methodology Single haematoxylin and eosin (H\&E) stained whole tumour slides of 929 of the 1141 early stage (high) intermediate risk EC of patients included in the post-operative radiation therapy in endometrial carcinoma (PORTEC)-1/-2 trials were available for review for the presence of MELF. Histological type, stage and grade, presence and extent of lymphvascular-space-invasion (LVSI), molecular subclass, L1-cell-adhesion-molecule (L1CAM) overexpression, and $\beta$-catenin exon-3 (CTNNB1) and KRAS mutational status were compared between MELF-positive and negative cases. Differences in patient and tumour characteristics were analysed with chisquare or Fisher's exact test for categorical and Mann-Whitney $U$ test for continuous variables. Time-to-event analyses were done using the Kaplan-Meier method, log-rank tests and Cox' proportional hazards models.

Abstract 577 Table 1 Clinicopathological features of MELF positive and negative cases

\begin{tabular}{|c|c|c|c|c|c|c|}
\hline & $\begin{array}{c}\text { Total } \\
(n=929)\end{array}$ & & $\begin{array}{l}\text { No MELF } \\
(n=800)\end{array}$ & & $\begin{array}{c}\text { MELF } \\
(n=129)\end{array}$ & P-value \\
\hline $\begin{array}{l}\text { Age } \\
\text { mean (range) }\end{array}$ & $68(67-68)$ & 68 & $(67-68)$ & 68 & $(67-69)$ & 0.88 \\
\hline $\begin{array}{l}\text { Histotype } \\
\text { endometrioid } \\
\text { non-endometrioid\# }\end{array}$ & $\begin{array}{ll}907 & (97.7 \%) \\
21 & (2.3 \%)\end{array}$ & $\begin{array}{l}781 \\
19\end{array}$ & $\begin{array}{l}(97.6 \%) \\
(2.4 \%)\end{array}$ & & $\begin{array}{l}(98.4 \%) \\
(1.6 \%)\end{array}$ & 0.54 \\
\hline $\begin{array}{l}\text { Stage } \\
\text { IA } \\
\geq 1 B^{*}\end{array}$ & $\begin{array}{ll}287 & (30.9 \%) \\
641 & (69,1 \%)\end{array}$ & $\begin{array}{l}280 \\
520\end{array}$ & $\begin{array}{l}(35.0 \%) \\
(65.0 \%)\end{array}$ & & $\begin{array}{l}(5.4 \%) \\
(94.6 \%)\end{array}$ & $<0.0001$ \\
\hline $\begin{array}{l}\text { Grade } \\
1-2 \\
3\end{array}$ & $\begin{array}{ll}792 & (85.3 \%) \\
136 & (14.7 \%)\end{array}$ & $\begin{array}{l}668 \\
132 \\
\end{array}$ & $\begin{array}{l}(83.5 \%) \\
(16.5 \%)\end{array}$ & $\begin{array}{l}125 \\
4\end{array}$ & $\begin{array}{l}(96.9 \%) \\
(3.1 \%)\end{array}$ & $<0.0001$ \\
\hline $\begin{array}{l}\text { IVSI } \\
\text { none or mild } \\
\text { substantial }\end{array}$ & $\begin{array}{ll}823 & (95.3 \%) \\
40 & (4.6 \%)\end{array}$ & $\begin{array}{l}712 \\
30\end{array}$ & $\begin{array}{l}(96.0 \%) \\
(4.0 \%)\end{array}$ & & $\begin{array}{l}(91.8 \%) \\
(8.2 \%)\end{array}$ & 0.06 \\
\hline $\begin{array}{l}\text { L1CAM } \\
\leq 10 \% \text { (negative) } \\
>10 \% \text { (positive) }\end{array}$ & $\begin{array}{ll}750 & (94.6 \%) \\
43 & (5.4 \%) \\
\end{array}$ & $\begin{array}{l}638 \\
41\end{array}$ & $\begin{array}{l}(94.0 \%) \\
(6.0 \%)\end{array}$ & $\begin{array}{l}113 \\
2\end{array}$ & $\begin{array}{l}(98.3 \%) \\
(1.7 \%)\end{array}$ & 0.03 \\
\hline $\begin{array}{l}\text { TCGA molecular } \\
\text { subgroups } \\
\text { POLE mutant } \\
\text { MMRd } \\
\text { p53 abnormal } \\
\text { NSMP }\end{array}$ & $\begin{array}{ll}57 & (7.1 \%) \\
226 & (28.2 \%) \\
38 & (4.7 \%) \\
480 & (60.0 \%)\end{array}$ & \begin{tabular}{|l}
55 \\
212 \\
37 \\
386
\end{tabular} & $\begin{array}{l}(8.0 \%) \\
(30.8 \%) \\
(5.4 \%) \\
(55.9 \%)\end{array}$ & $\begin{array}{l}2 \\
14 \\
1 \\
95\end{array}$ & $\begin{array}{l}(1.8 \%) \\
(12.5 \%) \\
(0.9 \%) \\
(84.8 \%)\end{array}$ & \\
\hline $\begin{array}{l}\text { CINNB-1 } \\
\text { wild type } \\
\text { mutation }\end{array}$ & $\begin{array}{ll}684 & (79.7 \%) \\
174 & (20.3 \%)\end{array}$ & $\begin{array}{l}575 \\
164 \\
\end{array}$ & $\begin{array}{l}(77.8 \%) \\
(22.2 \%)\end{array}$ & $\begin{array}{l}110 \\
10\end{array}$ & $\begin{array}{l}(91.7 \%) \\
(8.3 \%)\end{array}$ & $<0.0001$ \\
\hline $\begin{array}{l}\text { KRAS } \\
\text { wild type } \\
\text { mutation }\end{array}$ & $\begin{array}{ll}714 & (83.2 \%) \\
144 & (16.8 \%)\end{array}$ & $\begin{array}{l}623 \\
116\end{array}$ & $\begin{array}{l}(84.3 \%) \\
(15.7)\end{array}$ & $\begin{array}{l}92 \\
28\end{array}$ & $\begin{array}{l}(76.7 \%) \\
(23.3 \%)\end{array}$ & 0.05 \\
\hline
\end{tabular}


Abstract 577 Table 2 Multivariable analysis of risk factors for endometrial cancer recurrence

\begin{tabular}{|c|c|c|c|c|}
\hline Predictor & No. of cases & HR & $95 \% \mathrm{Cl}$ & $P$-value \\
\hline $\begin{array}{l}\text { Stage } \\
\text { IA } \\
\geq 1 \mathrm{~B}^{*} \\
\end{array}$ & $\begin{array}{l}192 \\
503 \\
\end{array}$ & 1.77 & 1.02 to 3.07 & 0.04 \\
\hline $\begin{array}{l}\text { Grade } \\
1-2 \\
3 \\
\end{array}$ & $\begin{array}{l}602 \\
93 \\
\end{array}$ & 2.42 & 1.28 to 4.58 & 0.01 \\
\hline $\begin{array}{l}\text { LVSI } \\
\text { none or mild } \\
\text { substantial }\end{array}$ & $\begin{array}{l}664 \\
31 \\
\end{array}$ & 3.90 & 2.07 to 7.37 & $<0.0001$ \\
\hline $\begin{array}{l}\text { LICAM } \\
\leq 10 \% \text { (negative) } \\
>10 \% \text { (positive) }\end{array}$ & $\begin{array}{l}659 \\
36 \\
\end{array}$ & 2.32 & 1.12 to 4.83 & 0.02 \\
\hline $\begin{array}{l}\text { TCGA } \\
\text { MMRd } \\
\text { POLE mutant } \\
\text { p53 abnormal } \\
\text { NSMP } \\
\end{array}$ & $\begin{array}{l}198 \\
43 \\
31 \\
423 \\
\end{array}$ & $\begin{array}{l}1 \\
0.34 \\
2.11 \\
0.70 \\
\end{array}$ & $\begin{array}{l}1 \\
0.08 \text { to } 1.46 \\
0.90 \text { to } 4.95 \\
0.41 \text { to } 1.18 \\
\end{array}$ & $\begin{array}{l}0.15 \\
0.09 \\
0.18 \\
\end{array}$ \\
\hline $\begin{array}{l}\text { CTNNB1 } \\
\text { wild type } \\
\text { mutated }\end{array}$ & $\begin{array}{l}558 \\
137 \\
\end{array}$ & 1.76 & 0.98 to 3.13 & 0.06 \\
\hline $\begin{array}{l}\text { MELF } \\
\text { none } \\
\text { present }\end{array}$ & $\begin{array}{l}594 \\
101 \\
\end{array}$ & 0.63 & 0.28 to 1.41 & 0.26 \\
\hline
\end{tabular}

Result(s)* MELF pattern of invasion was identified in 129 $(16 \%)$ cases, and was associated with grade 1-2 and deep myometrial invasion (table 1). MELF positive tumours were significantly more often found in the no-specific-molecularprofile (NSMP) subclass $(n=95,84.8 \%)$. Of these NSMP MELF positive tumours 91.1\% were CTNNB1-wildtype $(\mathrm{n}=82)$ and $26.5 \% \mathrm{KRAS}$-mutated $(\mathrm{n}=22)$. Uncorrected survival analysis showed a significantly favourable impact of MELF on risk of recurrence $(p=0.031)$. After correction for stage, grade, LVSI, molecular EC class, L1CAM and CTNNB1, MELF pattern of invasion did not significantly impact clinical outcome (HR 0.63 95\%CI 0.28 - 1.41, p=0.26), table 2 .

Conclusion* MELF-pattern of invasion was identified in $16 \%$ of early stage (high)intermediate risk EC, and had no independent prognostic impact. However, our results show that MELF pattern of invasion is more frequently found in NSMP KRAS-mutated EC without CTNNB1 mutations. These distinct molecular features could contribute to further refinement of the NSMP-subgroup of EC pointing to potential novel treatment targets.

\section{A DIAGNOSIS OF INFLAMMATORY MYOFIBROBLASTIC TUMOUR FOLLOWING LAPAROSCOPIC MYOMECTOMY WITH MORCELLATION: A CASE REPORT AND REVIEW OF THE LITERATURE}

${ }^{1} \mathrm{KW}$ Lee*, ${ }^{2} \mathrm{ZY} \mathrm{Ng},{ }^{3} \mathrm{~S}$ Mansor, ${ }^{2} \mathrm{IM}$ Aggarwal. 'KK Women's and Children's Hospital, Obstetrics and Gynaecology, Singapore; 'KK Women's and Children's Hospital, Gynaecological Oncology, Singapore; ${ }^{3} K K$ Women's and Children's Hospital, Pathology and Laboratory Medicine, Singapore

\subsection{6/ijgc-2021-ESGO.170}

Introduction/Background* Inflammatory myofibroblastic tumours (IMT) are rare spindle cell neoplasms of indeterminate malignant potential, commonly found in the lungs, but also originating from various organs ranging from head and neck, gastrointestinal to the genitourinary system. IMTs of the female gynaecological tract are rare and may mimic benign leiomyoma in both clinical presentation and appearance on imaging. We describe a case of uterine IMT, diagnosed after a laparoscopic myomectomy with in-bag morcellation.

Methodology
Result(s)* A 37-year-old woman was on follow-up for uterine mass on pelvic ultrasound, slowly enlarging to $3.3 \mathrm{~cm}$, presumed to be a fibroid. Although she did not have significant pressure symptoms or menorrhagia, she requested for removal and underwent laparoscopic myomectomy with morcellationin-bag.

Intra-operatively, a $6 \mathrm{~cm}$ mass was seen on the uterine posterior wall, macroscopically and morphologically consistent with that of benign leiomyoma. However, immunohistochemistry and molecular sequencing were positive for ALK-1 hence a diagnosis of IMT was made. Diffuse staining for desmin, $\mathrm{H}$ caldesmon and ER was also noted. Following a multi-disciplinary tumour board, consensus was for a CT scan of the thorax, abdomen and pelvis(which showed no extra-uterine spread) and for regular surveillance scans.

A review of the literature shows no universal consensus as to optimal treatment of uterine IMT. Majority of cases have been treated with surgical excision - open, laparoscopic or hysteroscopic. While most cases have a benign course with no recurrence/relapse, local recurrences are a known complication.

Given controversies in recent years over power morcellation potentially leading to dissemination of undiagnosed uterine leiomyosarcomas, morcellation-in-bag has become standard practice for all laparoscopic myomectomies or hysterectomies requiring morcellation. There is little data regarding outcomes of other types of uterine tumours, or IMT specifically, with regards to outcomes following morcellation. The only two documented cases in the literature specifically involving morcellation resulted in local recurrences requiring further treatment.

Conclusion* We present a case of uterine IMT diagnosed following laparoscopic myomectomy and in-bag morcellation. While the patient has no sign of extrauterine spread at present, further follow-up will be required to monitor for any progression or recurrence. Outcomes following morcellation or specific other treatment options will need to be further studied.

\section{IMPLEMENTATION OF COLLABORATIVE TRANSLATIONAL RESEARCH (TRANSPORTEC) FINDINGS IN AN INTERNATIONAL ENDOMETRIAL CANCER CLINICAL TRIALS PROGRAM (RAINBO)}

${ }^{1} \mathrm{~T}$ Bosse, ${ }^{2} \mathrm{M}$ Powell, ${ }^{3} \mathrm{E}$ Crosbie, ${ }^{4} \mathrm{~A}$ Leary, ${ }^{5} \mathrm{~J}$ Kroep, ${ }^{6} \mathrm{~K}$ Han, ${ }^{7} \mathrm{~J}$ Mcalpine, ${ }^{8} \mathrm{~N}$ Horeweg, ${ }^{8} \mathrm{~S}$ De Boer, ${ }^{9} \mathrm{M}$ De Bruyn, ${ }^{8} \mathrm{R}$ Nout, ${ }^{1} \mathrm{~V}$ Smit, ${ }^{9} \mathrm{HW}$ Nijman, ${ }^{10} \mathrm{~N}$ Singh, ${ }^{11} \mathrm{H}$ Mackay, ${ }^{3} \mathrm{R}$ Edmondson, ${ }^{12} \mathrm{~L}$ Mileshkin, ${ }^{13} \mathrm{D}$ Church, ${ }^{14} \mathrm{H}$ Kitchener, ${ }^{8} \mathrm{CL}$ Creutzberg. ${ }^{1}$ Leiden University ,Medical Center (LUMC), Pathology, Leiden, Netherlands; ${ }^{2}$ Barts Health NHS Trust, Clinical Oncology, London, UK; ${ }^{3}$ Manchester Academic Health Science Centre, St Mary's Hospital, Obstetrics and Gynaecology, Manchester, UK; ${ }^{4}$ Gustave Roussy Cancer Center, INSERM U981, Université Paris Saclay, Cancer Medicine and Gynecological Tumor Translational Research Lab, Villejuif, France; ${ }^{5}$ Leiden University Medical Center (LUMC), Medical Oncology, Leiden, Netherlands; ${ }^{6}$ Princess Margaret Cancer Centre, University of Toronto, Radiation Oncology, Toronto, Canada; ${ }^{7}$ University of British Columbia, Obstetrics and Gynecology, Vancouver, Canada; ${ }^{8}$ Leiden University Medical Center (LUMC), Radiation Oncology, Leiden, Netherlands; ' University Medical Center Groningen, Gynaecological Oncology, Groningen, Netherlands; ${ }^{10}$ Barts Health NHS Trust, Cellular Pathology, London, UK; ${ }^{11}$ Odette Cancer Center, Sunnybrook Health Sciences Centre, Medical Oncology, Toronto, Canada; ${ }^{12}$ Peter MacCallum Cancer Centre, Department of Medical Oncology, Melbourne, Australia; ${ }^{13}$ Oxford University Hospitals NHS Foundation Trust, Oxford NIHR Comprehensive Biomedical Research Centre, Oxford, UK; ${ }^{14}$ Institute of Cancer Sciences, University of Manchester, Women's Cancer Centre, Manchester, UK

10.1136/ijgc-2021-ESG0.171 